\title{
The Role of Tetrahydrobiopterin and Dihydrobiopterin in Ischemia/Reperfusion Injury When Given at Reperfusion
}

\author{
Qian Chen, Elizabeth Eun Jung Kim, Katrina Elio, Christopher Zambrano, Samuel Krass, \\ Jane Chun-wen Teng, Helen Kay, Kerry-Anne Perkins, Sailesh Pershad, Sloane McGraw, \\ Jeffrey Emrich, Jovan S. Adams, and Lindon H. Young
}

Department of Pathology, Microbiology and Immunology \& Forensic Medicine, Philadelphia College of Osteopathic Medicine, 4170 City Avenue, Philadelphia, PA 19131-1694, USA

Correspondence should be addressed to Lindon H. Young, lindonyo@pcom.edu

Received 13 August 2009; Revised 4 March 2010; Accepted 17 March 2010

Academic Editor: Owen Woodman

Copyright (C) 2010 Qian Chen et al. This is an open access article distributed under the Creative Commons Attribution License, which permits unrestricted use, distribution, and reproduction in any medium, provided the original work is properly cited.

\begin{abstract}
Reduced nitric oxide (NO) bioavailability and increased oxidative stress are major factors mediating ischemia/reperfusion $(\mathrm{I} / \mathrm{R})$ injury. Tetrahydrobiopterin $\left(\mathrm{BH}_{4}\right)$ is an essential cofactor of endothelial $\mathrm{NO}$ synthase (eNOS) to produce $\mathrm{NO}$, whereas dihydrobiopterin $\left(\mathrm{BH}_{2}\right)$ can shift the eNOS product profile from NO to superoxide, which is further converted to hydrogen peroxide $\left(\mathrm{H}_{2} \mathrm{O}_{2}\right)$ and cause $\mathrm{I} / \mathrm{R}$ injury. The effects of $\mathrm{BH}_{4}$ and $\mathrm{BH}_{2}$ on oxidative stress and postreperfused cardiac functions were examined in ex vivo myocardial and in vivo femoral I $(20 \mathrm{~min}) / \mathrm{R}(45 \mathrm{~min})$ models. In femoral $\mathrm{I} / \mathrm{R}, \mathrm{BH}_{4}$ increased NO and decreased $\mathrm{H}_{2} \mathrm{O}_{2}$ releases relative to saline control, and these effects correlated with improved postreperfused cardiac function. By contrast, $\mathrm{BH}_{2}$ decreased $\mathrm{NO}$ release relative to the saline control, but increased $\mathrm{H}_{2} \mathrm{O}_{2}$ release similar to the saline control, and these effects correlated with compromised postreperfused cardiac function. In conclusion, these results suggest that promoting eNOS coupling to produce $\mathrm{NO}$ and decrease $\mathrm{H}_{2} \mathrm{O}_{2}$ may be a key mechanism to restore postreperfused organ function during early reperfusion.
\end{abstract}

\section{Introduction}

The further damage caused by reperfusion following ischemia (I/R) has been a crucial event to attenuate in order to preserve more tissue or organ function $[1,2]$. Understanding mechanisms related to I/R injury in clinical cases involving myocardial infarction, coronary bypass/angioplasty, and organ transplantation provides a basis to develop new targets of intervention to attenuate the pathophysiological process. Reduced nitric oxide (NO) bioavailability and increased oxidative stress are major factors mediating I/R injury [3]. It has been shown that endothelium-derived $\mathrm{NO}$ is abruptly decreased within 5 minutes of reperfusion that results in endothelial dysfunction in myocardial $\mathrm{I} / \mathrm{R}(\mathrm{MI} / \mathrm{R})$ injury [3]. Endothelial dysfunction serves as a trigger to initiate the upregulation of endothelial cellular adhesion molecules to promote polymorphonuclear leukocyte (PMN) adherence and infiltration [3-5]. Subsequently, the transmigrated
PMNs release cytotoxic substances such as superoxide ( $\mathrm{SO}$ ) radicals to directly injure the myocardium and cause cardiac contractile dysfunction $[4,6]$.

It is well known that vascular $\mathrm{NO}$ is produced by endothelial NO synthase (eNOS) by converting L-arginine to L-citrulline in the presence of molecular oxygen. Tetrahydrobiopterin $\left(\mathrm{BH}_{4}\right)$ is an essential cofactor of eNOS to aid in the coupling between L-arginine and the heme site within the oxygenase domain of eNOS [7]. Under this coupled state, eNOS produces NO to facilitate normal blood flow and to maintain an antiinflammatory and antithrombotic vascular endothelial surface [8]. By contrast, dihydrobiopterin $\left(\mathrm{BH}_{2}\right)$, an oxidized form of $\mathrm{BH}_{4}$, can cause uncoupling between L-arginine and eNOS. Under this condition, eNOS utilizes molecular oxygen as the substrate in the absence of Larginine to generate $\mathrm{SO}$ instead of $\mathrm{NO}$ [9-11]. SO is further converted into hydrogen peroxide $\left(\mathrm{H}_{2} \mathrm{O}_{2}\right)$ by superoxide dismutase. Moreover, incomplete oxidative phosphorylation 
in dysfunctional mitochondria in murine endothelial cells can facilitate additional oxidation of $\mathrm{BH}_{4}$ to $\mathrm{BH}_{2}$, thus increasing the $\mathrm{BH}_{2}$ to $\mathrm{BH}_{4}$ ratio to further promote eNOS uncoupling [12, 13]. With this regard, eNOS uncoupling may induce $\mathrm{NO}$ insufficiency, but also contribute to the oxidative stress under various pathological conditions, such as I/R. Previous studies evaluated that increasing eNOS activity with PKC epsilon activator resulted in compromised postreperfused heart function, whereas decreasing eNOS activity with PKC epsilon inhibitor resulted in restoration of postreperfused cardiac function associated with decreased $\mathrm{H}_{2} \mathrm{O}_{2}$ release in rat femoral artery/vein subjected to I/R [12]. By contrast, a nonselective NOS inhibitor, $N^{G}$-nitroL-arginine methyl ester (L-NAME), does not appreciably inhibit SO release from NOS and consequently is not associated with improvement of cardiac function in many MI/R models [11, 14].

Regarding $\mathrm{BH}_{4}$, previous studies have shown that $\mathrm{BH}_{4}$ given prior to myocardial ischemia significantly restored post-reperfusion cardiac function in the isolated perfused rat heart and enhanced nitrite levels in the coronary perfusate [15]. Although, the potential opposing effects of $\mathrm{BH}_{2}$ were not investigated in the Yamashiro et al. study. In addition, the role of $\mathrm{BH}_{4}$ or $\mathrm{BH}_{2}$ mediating eNOS coupling or uncoupling exclusively during the early reperfusion has not been assessed in real-time in vivo or ex vivo. This is clinically important in that pretreatment may not be an option in clinical settings whereas treatment during the early reperfusion would be more practical and helpful to improve the organ function.

Therefore, in this study, $\mathrm{BH}_{4}$ was used during the early reperfusion within 5 minutes to promote the eNOS coupled state, whereas $\mathrm{BH}_{2}$ was utilized to further maintain the eNOS uncoupled state. The following hypotheses were tested. Firstly, the effects of $\mathrm{BH}_{4}$ or $\mathrm{BH}_{2}$ on vascular $\mathrm{NO}$ release were tested by directly measuring NO release from nonischemic rat aortic segments and from femoral arteries/veins subjected to $\mathrm{I} / \mathrm{R}$ in anesthetized rats. Secondly, the effects of $\mathrm{BH}_{4}$ or $\mathrm{BH}_{2}$ on oxidative stress (i.e., $\mathrm{H}_{2} \mathrm{O}_{2}$ ) were recorded by directly measuring $\mathrm{H}_{2} \mathrm{O}_{2}$ release from femoral arteries/veins subjected to $\mathrm{I} / \mathrm{R}$ in anesthetized rats. Thirdly, the effects of $\mathrm{BH}_{4}$ or $\mathrm{BH}_{2}$ on postreperfused cardiac function and PMN vascular adherence/infiltration were determined in a PMNinduced MI/R injury animal model. Then L-NAME was used to test if the cardioprotection and decreased PMN adherence/infiltration provided by $\mathrm{BH}_{4}$ could be blocked to indicate a NO mechanism involved in this cardioprotection.

\section{Methods}

2.1. In Vitro Measurement of NO Release from Rat Aortic Segments. The Institutional Animal Care and Use Committee of Philadelphia College of Osteopathic Medicine approved all animal protocols performed in this study. As previously described, the isolated rat aortas were cut to 6$7 \mathrm{~mm}$ long (i.e., $10 \mathrm{mg}$ wet weight) after removal of adherent fat and connective tissue. Then these aortic rings were cut open and fixed by pins with the endothelial surface facing up in 24-well culture dishes containing $1 \mathrm{~mL}$ oxygenated Krebs'-Henselit (K-H) solution maintained at $37^{\circ} \mathrm{C}$ (in
TABLE 1: The effects of $\mathrm{BH}_{4}$ or $\mathrm{BH}_{2}$ on $\mathrm{NO}$ release from nonischemic rat aortic segments.

\begin{tabular}{lcc}
\hline Basal/Treatments & $\begin{array}{c}\text { NO release } \\
\text { (picomoles/mg tissue) }\end{array}$ & Sample No. \\
\hline Basal & $2.28 \pm 0.25$ & $n=17$ \\
Ach $(5 \mu \mathrm{M})$ & $5.38 \pm 0.70^{* *}$ & $n=20$ \\
$\mathrm{BH}_{4}(1 \mu \mathrm{M})$ & $2.74 \pm 0.16$ & $n=14$ \\
$\mathrm{BH}_{4}(10 \mu \mathrm{M})$ & $4.45 \pm 0.43^{*}$ & $n=21$ \\
$\mathrm{BH}_{4}(20 \mu \mathrm{M})$ & $4.88 \pm 0.50^{* *}$ & $n=24$ \\
$\mathrm{BH}_{4}(40 \mu \mathrm{M})$ & $5.01 \pm 0.61^{* *}$ & $n=21$ \\
$\mathrm{BH}_{2}(50 \mu \mathrm{M})$ & $0.87 \pm 0.33^{\# \#}$ & $n=21$ \\
$\mathrm{BH}_{2}(100 \mu \mathrm{M})$ & $0.86 \pm 0.23^{\# \#}$ & $n=25$ \\
$\mathrm{BH}_{2}(200 \mu \mathrm{M})$ & $0.78 \pm 0.33^{\# \#}$ & $n=14$ \\
$\mathrm{Ach}^{*}(5 \mu \mathrm{M})+\mathrm{L}-\mathrm{NAME}$ & $-0.59 \pm 0.38$ & $n=5$ \\
$(800 \mu \mathrm{M})$ & & $n=8$ \\
$\mathrm{BH}_{4}(10 \mu \mathrm{M})+\mathrm{L}-\mathrm{NAME}$ & $-1.14 \pm 0.48$ & $n=8$ \\
$(800 \mu \mathrm{M})$ & & \\
$\mathrm{BH}_{2}(100 \mu \mathrm{M})+\mathrm{L}-\mathrm{NAME}$ & $-1.70 \pm 0.34$ & \\
$(800 \mu \mathrm{M})$ & & \\
\hline
\end{tabular}

${ }^{*} P<.05,{ }^{*} P<.01$ compared to basal NO release; ${ }^{\#} P<.01$ compared to the effects of $\mathrm{BH}_{4}$ on $\mathrm{NO}$ release.

mmol/L: 10.0 dextrose, $119.0 \mathrm{NaCl}, 12.5 \mathrm{NaHCO}_{3}, 2.5$ $\mathrm{CaCl}_{2}, 4.8 \mathrm{KCl}, 1.2 \mathrm{KH}_{2} \mathrm{PO}_{4}$, and $\left.1.2 \mathrm{MgSO}_{4}\right)$. The $\mathrm{NO}$ release was measured using a calibrated $\mathrm{NO}$ meter (IsoNO; World Precision Instruments, Sarasota, FL) connected to a polygraph internally shielded NO electrode [16]. Basal rat aortic endothelial NO release was determined by the difference of reading between a well containing only $\mathrm{K}-\mathrm{H}$ buffer and the well containing aortic tissue as in previous studies [17]. After basal NO measurement, the effects of acetylcholine (Ach, $5 \mu \mathrm{M})$ and $\mathrm{BH}_{4}(1-40 \mu \mathrm{M})$ or $\mathrm{BH}_{2}(50-$ $200 \mu \mathrm{M}$ ) were determined. Ach was used as a positive control to assess the viability of the endothelium. Then $800 \mu \mathrm{M} \mathrm{L}$ NAME was added to the K-H buffer solution; the effects of Ach $(5 \mu \mathrm{M}), \mathrm{BH}_{4}(10 \mu \mathrm{M})$, or $\mathrm{BH}_{2}(100 \mu \mathrm{M})$ were reassessed 30 minutes later to evaluate if L-NAME could block NO release. All measurements were reported in picomoles per milligram of aortic tissue. The number of trials for each group was indicated in Table 1.

2.2. In Vivo Measurement of $\mathrm{NO} / \mathrm{H}_{2} \mathrm{O}_{2}$ Release from Rat Femoral Veins during Reperfusion. $\mathrm{NO}$ or $\mathrm{H}_{2} \mathrm{O}_{2}$ release was measured from femoral veins in anesthetized rats, one subjected to I/R and the other is a nonischemic sham control. This rat femoral I/R model was based on the procedure of Kuntscher et al. [18]. The $\mathrm{NO}$ or $\mathrm{H}_{2} \mathrm{O}_{2}$ microsensors ( $100 \mu \mathrm{m}$ diameter) connected to a free radical analyzer (Apollo 4000; World Precision Instruments, Sarasota, FL) were inserted into a catheter and placed inside each femoral vein as previously published [12]. Ischemia of femoral circulation in one side would be induced by clamping the femoral artery/vein for 20 minutes followed by 45 minutes reperfusion via releasing the clamp, which was similar to the MI/R time course. $\mathrm{BH}_{4}(6.5 \mathrm{mg} / \mathrm{kg}$, which corresponds to about $250 \mu \mathrm{M}$ in the blood concentration), $\mathrm{BH}_{2}$ (2 or 


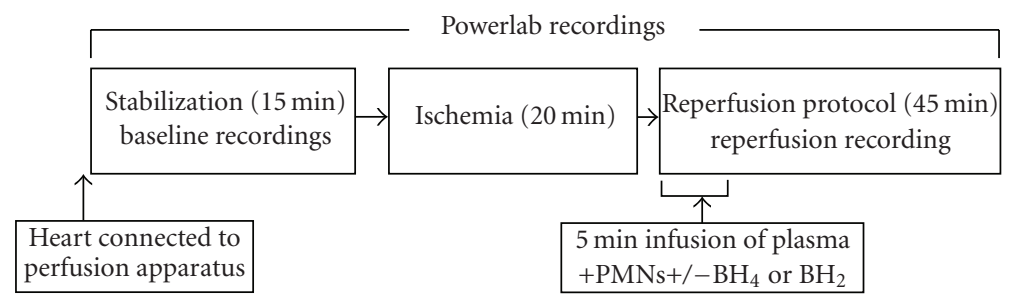

FIGURE 1: Schematic diagram of the ischemia/reperfusion protocol in the isolated perfused rat heart model.

$4 \mathrm{mg} / \mathrm{kg}$, which corresponds to about 100 or $200 \mu \mathrm{M}$ in the blood concentration), or saline (for nondrug control group) was applied through tail vein injection at the beginning of reperfusion. The total volume of solution was $1 \mathrm{~mL}$ saline or drug mixed with saline. $\mathrm{NO}$ or $\mathrm{H}_{2} \mathrm{O}_{2}$ release was continuously recorded and collected at 5 minutes intervals during a 15-minute baseline period, 20-minute ischemia and 45 -minute reperfusion. The changes in $\mathrm{NO}$ or $\mathrm{H}_{2} \mathrm{O}_{2}$ release during reperfusion (in $\mathrm{pA}$ ) were expressed as relative changes to baseline (initial). Thereafter, the values were converted to the concentration of $\mathrm{NO}(\mathrm{nM})$ or $\mathrm{H}_{2} \mathrm{O}_{2}(\mu \mathrm{M})$ after correction to the preexperimental calibration curve of $\mathrm{NO}$ or $\mathrm{H}_{2} \mathrm{O}_{2}$ microsensors.

2.3. Isolated Rat Heart Preparation. After injecting pentobarbital sodium $(60 \mathrm{mg} / \mathrm{kg})$ and sodium heparin $(1,000 \mathrm{U})$ intraperitoneally (i.p.), hearts were rapidly excised from male Sprague Dawley rats (275-325 g, Ace Animals, Boyertown, PA) [19]. Then the heart was subjected to retrograde perfusion with a modified Krebs' buffer composed of 17.0 dextrose, $120.0 \mathrm{NaCl}, 25.0 \mathrm{NaHCO}_{3}, 2.5 \mathrm{CaCl}_{2}, 0.5$ EDTA, $5.9 \mathrm{KCl}$, and $1.2 \mathrm{MgCl}_{2}$ (in $\mathrm{mmol} / \mathrm{L}, 37^{\circ} \mathrm{C}, \mathrm{pH}$ of 7.3-7.4). Three side arms in the perfusion line proximal to the heart inflow cannula, allowed perfusing $\mathrm{BH}_{4}$ or $\mathrm{BH}_{2} /$ plasma, PMNs, and L-NAME. Coronary flow was monitored by a flowmeter (T106, Transonic Systems, Inc., Ithaca, NY). Left ventricular-developed pressure (LVDP, defined as left ventricular end-systolic pressure minus left ventricular end-diastolic pressure) and the maximal rate of LVDP $\left(+d P / d t_{\max }\right)$ were monitored using a pressure transducer (SPR-524, Millar Instruments, Inc., Houston, TX), which was positioned in the left ventricular cavity. LVDP, $+d P / d t_{\max }$, and coronary flow were measured every 5 minutes for 15 minutes baseline recording; 20-minute global ischemia was induced by stopping perfusion (i.e., turning stop-cock to off position) and 45-minute reperfusion. The schematic protocol is shown in Figure 1. All data were recorded using a Powerlab Station acquisition system (ADInstruments, Grand Junction, CO) in conjunction with a computer (Gateway).

The isolated rat heart was cannulated via the aorta onto a perfusion needle and was immersed in a water-jacketed reservoir that contains $160 \mathrm{~mL}$ of Krebs' buffer maintained at $37^{\circ} \mathrm{C}$. The preload volume came from Krebs' buffer that filled the left ventricle upon insertion of the pressure transducer catheter in the base of the left side of the heart.
TABLE 2: Experimental groups in observation of postreperfused cardiac function from the isolated perfused rat heart.

\begin{tabular}{lcccc}
\hline Group & Sham I/R & I/R & I/R+PMN & $\begin{array}{c}\text { I/R+PMN+L- } \\
\text { NAME }\end{array}$ \\
\hline $\begin{array}{l}\text { Control } \\
\text { No Drug) }\end{array}$ & $n=6$ & $n=7$ & $n=9$ & \\
$\mathrm{BH}_{4}(1 \mu \mathrm{M})$ & & & $n=6$ & \\
$\mathrm{BH}_{4}(5 \mu \mathrm{M})$ & & & $n=6$ & \\
$\mathrm{BH}_{4}(10 \mu \mathrm{M})$ & $n=6$ & $n=7$ & $n=6$ & $n=6$ \\
$\mathrm{BH}_{2}(100 \mu \mathrm{M})$ & $n=4$ & $n=5$ & $n=7$ & \\
\hline
\end{tabular}

We also used animals in the same weight range for all study groups and therefore the preload should be similar among all study groups as in previous studies $[17,19,20]$. The initial baseline left ventricular end-diastolic pressure was between 4-8 $\mathrm{mmHg}$ for all hearts in each study group.

2.4. Groups of Isolated Perfused Hearts. Table 2 indicates the 12 groups (control and treatment conditions) of isolated perfused rat hearts used in the study. Three types of control groups were used in the study based on the well-established PMN-induced MI/R model [21]. (1) Sham hearts were not subjected to ischemia and are not perfused with PMNs, but they were perfused with $5 \mathrm{~mL}$ of plasma $(1 \mathrm{~mL} / \mathrm{min})$ at 35 minutes into perfusion (i.e., the same time point that I/R hearts would be given $5 \mathrm{~mL}$ of plasma: 15 minutes of baseline recordings plus $20 \mathrm{~min}$ ischemia). This group was employed to show that cardiac function (i.e., LVDP and $\left.+d P / d t_{\max }\right)$ could be maintained throughout the $80-$ minute protocol. (2) I/R hearts were subjected to 20 minutes of ischemia/45 minutes of reperfusion, and were perfused with $5 \mathrm{~mL}$ of plasma $(1 \mathrm{~mL} / \mathrm{min})$ in the absence of PMNs during the first 5 minutes of reperfusion. This group was employed to show that these hearts would recover to near baseline values by the end of 45-minute reperfusion. Twentyminute ischemia followed by 45 -minute reperfusion would stun the heart but was a form of reversible cell injury. (3) $\mathrm{I} / \mathrm{R}+\mathrm{PMN}$ hearts were subjected to 20 minutes of ischemia and were reperfused with PMNs $\left(200 \times 10^{6}\right.$, resuspended in $5 \mathrm{~mL}$ Krebs' buffer) and $5 \mathrm{~mL}$ of plasma $(1 \mathrm{~mL} / \mathrm{min})$ during the first 5 minutes of reperfusion. This group was employed to show that 20 minutes of ischemia followed by 45 minutes of reperfusion in the presence of PMNs resulted in a sustained cardiac contractile dysfunction throughout the 
45-minute reperfusion period compared to initial baseline values. Previous studies showed that sham hearts given PMNs exhibited no changes from initial control values [19]. This result indicated that PMNs without ischemia were not sufficient to induce sustained cardiac dysfunction. In some sham and I/R hearts, $\mathrm{BH}_{4}(10 \mu \mathrm{M})$ or $\mathrm{BH}_{2}(100 \mu \mathrm{M})$ was dissolved in plasma and infused at a rate of $1 \mathrm{~mL} / \mathrm{min}$ for 5 minutes at 35 minutes into perfusion (sham) or at the beginning of reperfusion. These groups were employed to show that $\mathrm{BH}_{4}$ or $\mathrm{BH}_{2}$ did not exert a cardiotonic or cardiodepressant effect in sham or $\mathrm{I} / \mathrm{R}$ settings at this concentration. In some I/R+PMN hearts, different doses of $\mathrm{BH}_{4}(1-10 \mu \mathrm{M})$ or $\mathrm{BH}_{2}(100 \mu \mathrm{M})$ were infused at a rate of $1 \mathrm{~mL} / \mathrm{min}$ for 5 minutes at the beginning of reperfusion to test whether $\mathrm{BH}_{4}$ or $\mathrm{BH}_{2}$ might elicit cardioprotective effects. Furthermore, a NO synthase inhibitor, L-NAME $(50 \mu \mathrm{M})$, was used throughout the 45 minutes of reperfusion in some $\mathrm{BH}_{4}$-treated $\mathrm{I} / \mathrm{R}+\mathrm{PMN}$ hearts to determine if a NO mechanism was involved in the cardioprotective effect. The dose of L-NAME $(50 \mu \mathrm{M})$ used in this study does not significantly affect LVDP in sham hearts [22].

2.5. Isolation of Plasma. Blood was collected from the aorta in citrate phosphate buffer (Sigma Chemical Co., St. Louis, $\mathrm{MO}$ ) just before isolation of the rat heart and centrifuged at $10,000 \mathrm{~g}$ for 10 minutes at $4^{\circ} \mathrm{C}$. Then $5 \mathrm{~mL}$ of plasma were decanted and used for infusion for all cardiac perfusion groups [19].

2.6. Isolation of PMNs. PMNs were prepared from Male Sprague Dawley rats (350-400 g, Ace Animals, Boyertown, PA). After injection (i.p.) of $0.5 \%$ glycogen (Sigma Chemical Co., St. Louis, MO) for 16-18 hours, PMNs were harvested by peritoneal lavage in $30 \mathrm{~mL}$ of $0.9 \% \mathrm{NaCl}$ and centrifuged to remove the debris, as previously described [17]. The PMN preparations were $>90 \%$ pure and $>95 \%$ viable, according to microscopic analysis and exclusion of $0.3 \%$ trypan blue, respectively.

\subsection{Determination of PMN Vascular Adherence and Infiltra-} tion into the Cardiac Tissue. Three rat hearts that were closest to the group mean for the cardiac function studies from each group were used for histological analysis. The hearts were dehydrated in graded ice-cold acetone washes (50-100\%) and embedded in plastic and sectioned into $2.5 \mu \mathrm{m}$ serial sections. Then sections were stained with hematoxylin and eosin by previously established methods [17]. Under light microscopy, 10 areas of each rat heart from the left ventricle were counted for PMN vascular adherence and infiltration into the heart tissue and expressed as adhered and total $\mathrm{PMNs} / \mathrm{mm}^{2}$.

2.8. Statistical Analysis. All data in the text and figures were presented as means \pm SEM. The data from more than two groups were analyzed by ANOVA. The data from only two groups were analyzed by student $t$-test. Probability values of $<.05$ were considered to be statistically significant.

\section{Results}

3.1. $\mathrm{BH}_{4}$ or $\mathrm{BH}_{2}$ on Endothelial $\mathrm{NO}$ Release. NO release from rat nonischemic aortic endothelium was measured to determine the effects of $\mathrm{BH}_{4}$ or $\mathrm{BH}_{2}$ on $\mathrm{NO}$ release. Moreover, the dose-responses of $\mathrm{BH}_{4}$ and $\mathrm{BH}_{2}$ on $\mathrm{NO}$ release also provide the optimal dose ranges for testing their effects in oxidative stress and postreperfused cardiac function during $\mathrm{I} / \mathrm{R}$. As shown in Table $1, \mathrm{BH}_{4}$ dose dependently increased $\mathrm{NO}$ release, whereas $\mathrm{BH}_{2}$ dose dependently decreased NO release from aortic segments. The basal endothelial NO release was $2.28 \pm 0.25$ picomoles $\mathrm{NO} / \mathrm{mg}$ tissue. $\mathrm{BH}_{4}$ $(10 \mu \mathrm{M}, 20 \mu \mathrm{M}$, and $40 \mu \mathrm{M})$ produced a significant increase in NO release above basal to $4.45 \pm 0.43(P<.05), 4.88$ $\pm 0.50(P<.01)$, and $5.01 \pm 0.61(P<.01)$ picomoles $\mathrm{NO} / \mathrm{mg}$ tissue, respectively. By contrast, $\mathrm{BH}_{2}(50 \mu \mathrm{M}, 100 \mu \mathrm{M}$ and $200 \mu \mathrm{M}$ ) dose dependently decreased endothelial NO release. The decreases in $\mathrm{NO}$ release by $\mathrm{BH}_{2}$ were significant from the increasing $\mathrm{NO}$ releases by $\mathrm{BH}_{4}$ (all $\left.P<.01\right)$. Ach $(5 \mu \mathrm{M})$ was used as a positive control in this assay and stimulated the endothelium causing an increase to 5.38 \pm 0.70 picomoles $\mathrm{NO} / \mathrm{mg}$ tissue $(P<.01)$. The NOS inhibitor, L-NAME ( $800 \mu \mathrm{M})$, served as negative control, and significantly blocked $\mathrm{NO}$ release from aortic endothelium in presence of Ach and $\mathrm{BH}_{4}$.

\subsection{Effects of $\mathrm{BH}_{4}$ or $\mathrm{BH}_{2}$ on $\mathrm{H}_{2} \mathrm{O}_{2}$ Release from Rat Femoral} Veins during Reperfusion. The femoral vein subjected to $\mathrm{I} / \mathrm{R}$ in saline control rats exhibited a significant increase in $\mathrm{H}_{2} \mathrm{O}_{2}$ release (i.e., up to $3.2 \mu \mathrm{M}$ ) throughout reperfusion compared to sham vein (Figure 2(a)). This data supports the concept that oxidative stress is increased during reperfusion. Furthermore, $\mathrm{H}_{2} \mathrm{O}_{2}$ release increased in $2 \mathrm{mg} / \mathrm{kg} \mathrm{BH}$-treated animals similar to saline control (Figure 2(b)) in that $\mathrm{H}_{2} \mathrm{O}_{2}$ release significantly increased in the $\mathrm{I} / \mathrm{R}$ limb relative to the sham limb throughout the 45 minutes of reperfusion. $\mathrm{H}_{2} \mathrm{O}_{2}$ release increased in the saline and $\mathrm{BH}_{2}$-treated animals by $2.6 \mu \mathrm{M}$ and $3.5 \mu \mathrm{M}$, respectively during the first 5 minutes of reperfusion and remained elevated by $3.2 \mu \mathrm{M}$ and $2.1 \mu \mathrm{M}$, respectively, by 45 minutes of reperfusion (Figure 2(b)). By contrast, applying $6.5 \mathrm{mg} / \mathrm{kg} \mathrm{BH}_{4}$ at the start of reperfusion decreased $\mathrm{H}_{2} \mathrm{O}_{2}$ release (i.e., down to $0.84 \mu \mathrm{M}$ ) in the femoral $\mathrm{I} / \mathrm{R}$ vein during the whole 45 minutes of reperfusion which was significant at 45 minutes of reperfusion in comparison with the saline control femoral $I / R$ vein regarding the relative difference in each of their sham femoral veins, respectively (Figure 2(b)). These findings indicated that $\mathrm{BH}_{4}$ applied at the beginning of reperfusion decreased the oxidative stress during reperfusion, whereas $\mathrm{BH}_{2}$ administration was similar to saline control and did not further increase the oxidative stress.

3.3. Effects of $\mathrm{BH}_{4}$ or $\mathrm{BH}_{2}$ on $\mathrm{NO}$ Release from Rat Femoral Veins during Reperfusion. Compared to sham vein, the femoral vein subjected to $\mathrm{I} / \mathrm{R}$ in saline control rats exhibited a slight increase in NO release for the first 5 minutes of reperfusion (i.e., up to $8.2 \mathrm{nM}$ ), and then gradually decreased for the rest of reperfusion (i.e., decreased by $6.6 \mathrm{nM}$ from baseline) (Figure $3(\mathrm{a})$ ). The initial increase may be due to 


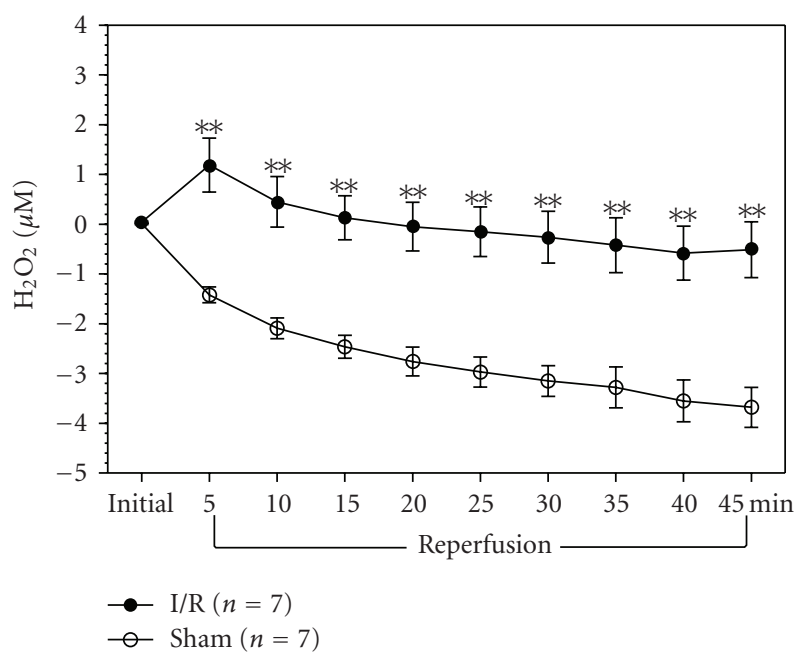

(a)

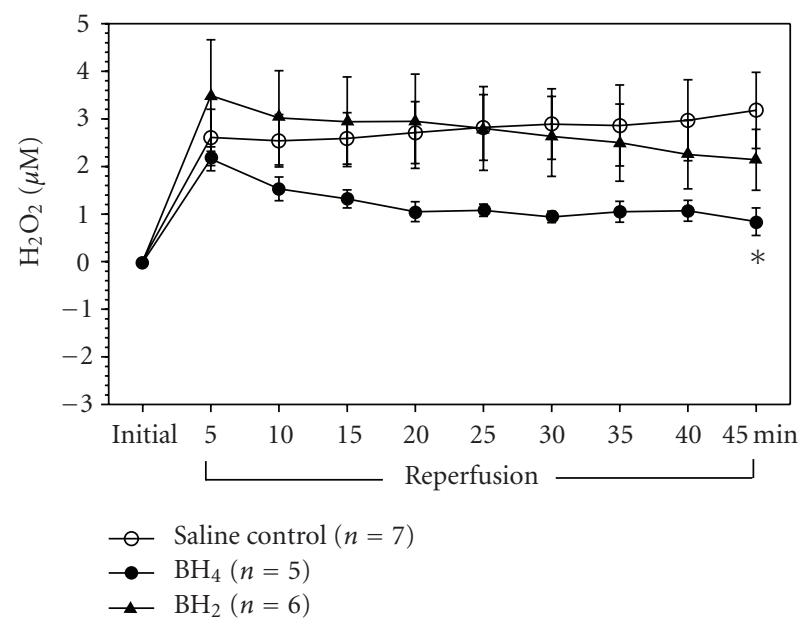

(b)

Figure 2: Measurement of $\mathrm{H}_{2} \mathrm{O}_{2}(\mu \mathrm{M})$ release from rat femoral veins during reperfusion in the saline control group and $\mathrm{BH}_{4}{ }^{-}$or $\mathrm{BH}_{2}$-treated group. (a) $\mathrm{H}_{2} \mathrm{O}_{2}(\mu \mathrm{M})$ releases from rat sham and $\mathrm{I} / \mathrm{R}$ femoral veins during reperfusion in the saline control group. Anesthetized rats were given saline via tail vein at the beginning of reperfusion $(n=7)$. There was a significant increase in $\mathrm{H}_{2} \mathrm{O}_{2}$ release from $\mathrm{I} / \mathrm{R}$ veins compared to sham veins during reperfusion. $\left({ }^{* *} \mathrm{P}<\right.$ .01 from sham limb) (b) The relative difference in $\mathrm{H}_{2} \mathrm{O}_{2}$ release between $\mathrm{I} / \mathrm{R}$ and sham femoral veins in the saline control group $(n=7), \mathrm{BH}_{4}(6.5 \mathrm{mg} / \mathrm{kg})$ treated group $(n=5)$, and $\mathrm{BH}_{2}(2 \mathrm{mg} / \mathrm{kg})$ treated group $(n=6) . \mathrm{BH}_{4}$ or $\mathrm{BH}_{2}$ was given via tail vein at the beginning of reperfusion. $\mathrm{BH}_{4}$ treatment significantly decreased $\mathrm{H}_{2} \mathrm{O}_{2}$ release at 45-minute reperfusion compared to saline control. ( ${ }^{*} P<.05$ from saline control group).

the shear wall stress after restoration of blood flow. Applying $4 \mathrm{mg} / \mathrm{kg} \mathrm{BH}$ at the beginning of reperfusion significantly decreased NO release (i.e., decreased by $220 \mathrm{nM}$ ) from 20 minutes to 45 minutes of reperfusion (all $\mathrm{P}<.01$ ) in comparison with the saline control femoral $I / R$ vein regarding the relative difference in each of their sham femoral veins, respectively (Figure $3(\mathrm{~b})$ ). By contrast, $6.5 \mathrm{mg} / \mathrm{kg} \mathrm{BH} 4$ showed a significant increase in NO release from 20 minutes

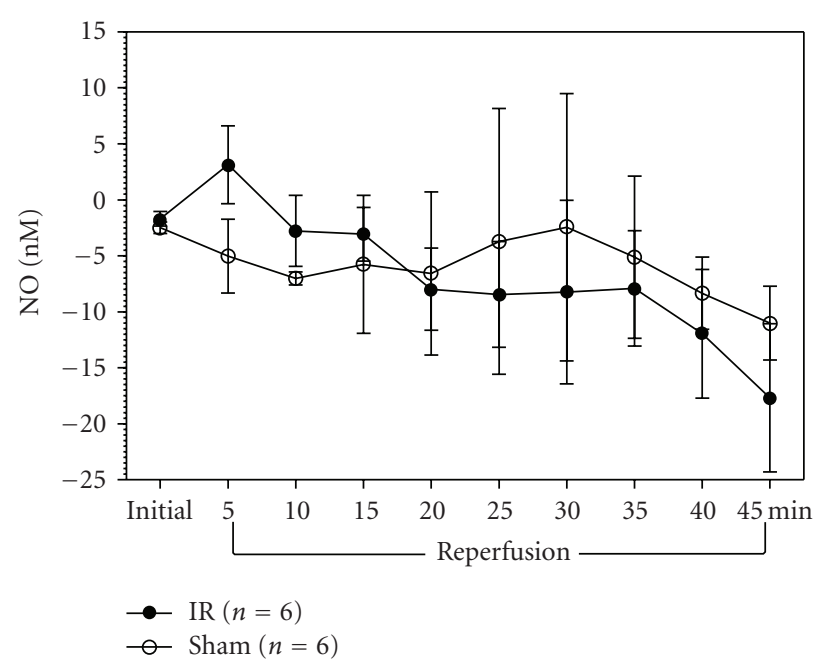

(a)

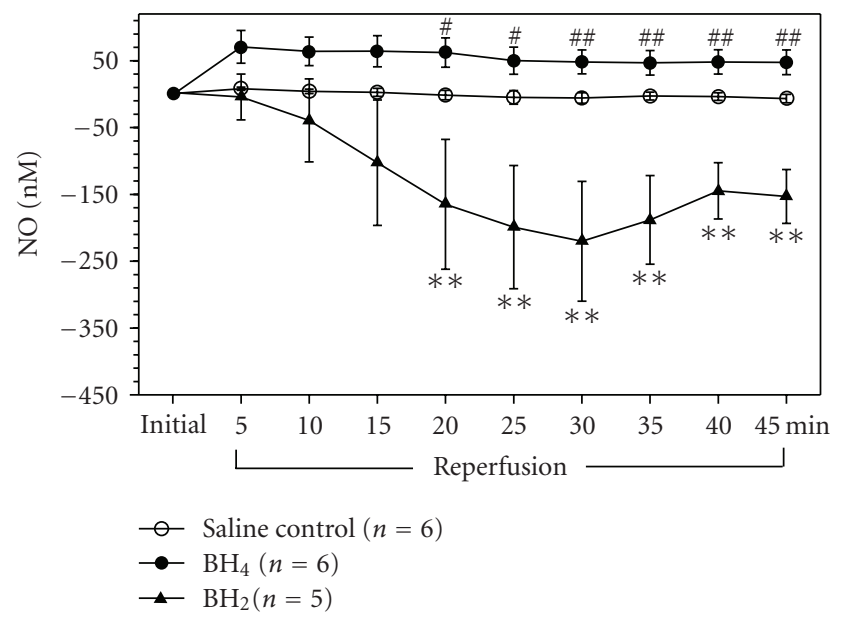

(b)

Figure 3: Measurement of NO (nM) release from rat femoral veins during reperfusion in the saline control group and $\mathrm{BH}_{4}-$ or $\mathrm{BH}_{2}$ treated group. (a) NO (nM) releases from rat sham and I/R femoral veins during reperfusion in the saline control group. Anesthetized rats were given saline via tail vein at the beginning of reperfusion $(n=6)$. There was a slight decrease in NO release from I/R veins compared to sham veins after 20 minutes of reperfusion. (b) The relative difference in $\mathrm{NO}$ release between I/R and sham femoral veins in the saline control group $(n=6), \mathrm{BH}_{4}(6.5 \mathrm{mg} / \mathrm{kg})$-treated group $(n=6)$, and $\mathrm{BH}_{2}(4 \mathrm{mg} / \mathrm{kg})$-treated group $(n=5) . \mathrm{BH}_{4}$ or $\mathrm{BH}_{2}$ was given via tail vein at the beginning of reperfusion. $\mathrm{BH}_{2}$ treatment significantly decreased $\mathrm{NO}$ release from 20 minutes and throughout the rest of reperfusion. $\mathrm{BH}_{4}$ treatment significantly increased NO release from 20 minutes to 45 -minute reperfusion compared to $\mathrm{BH}_{2}$ treatment. $\left({ }^{*} P<.05,{ }^{* *} P<.01\right.$ from saline control group; ${ }^{\#} P<.05,{ }^{\# \#} P<.01$ from $\mathrm{BH}_{2}$-treated group).

$(P<.05)$ to 45 minutes reperfusion $(P<.01)$ (i.e., up to $268 \mathrm{nM}$ ) comparing to $\mathrm{BH}_{2}$ treatment (Figure 3(b)). This data indicated that $\mathrm{BH} 2$ applied at the beginning of reperfusion significantly decreased NO release during reperfusion, whereas $\mathrm{BH}_{4}$ administration significantly increased $\mathrm{NO}$ release compared to $\mathrm{BH}_{2}$ treatment. 


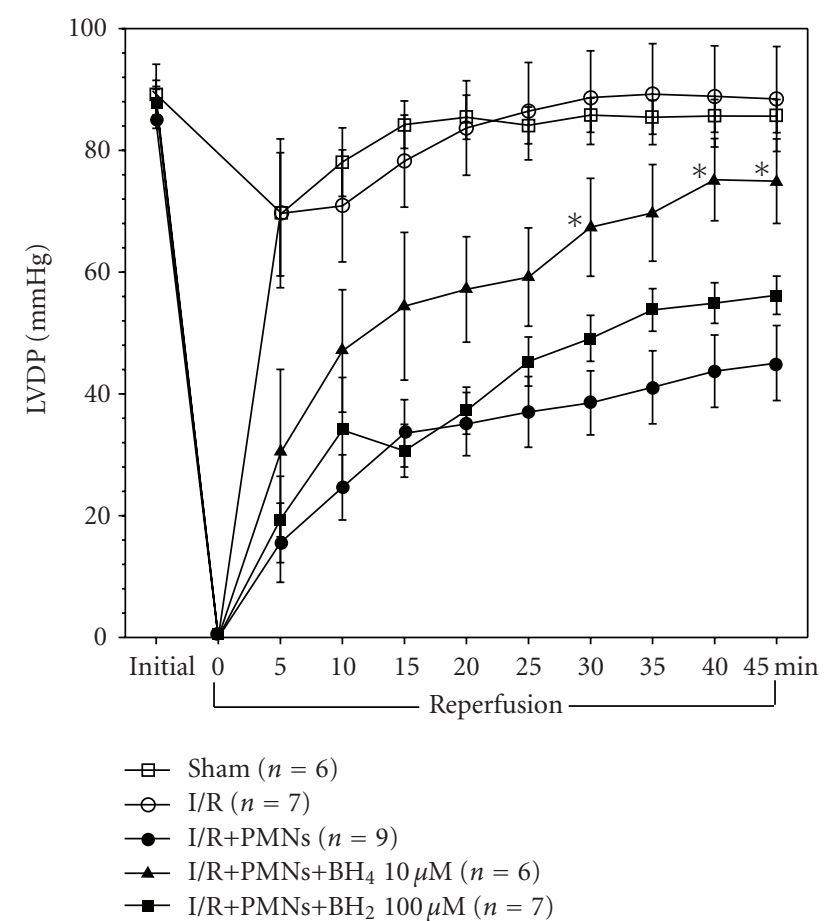

FIGURE 4: Time course of cardiac function parameters (LVDP) from sham, I/R, I/R+PMN, I/R+PMN+BH $\quad(10 \mu \mathrm{M})$, and $\mathrm{I} / \mathrm{R}+\mathrm{PMN}+\mathrm{BH}_{2} \quad(100 \mu \mathrm{M})$ groups. There was no significant difference in baseline values among these groups. The sham group $(n=6)$ maintained the same LVDP throughout the 80 minutes protocol. The I/R+PMN $(n=9)$ and $\mathrm{I} / \mathrm{R}+\mathrm{PMN}+\mathrm{BH}_{2}(n=7)$ groups exhibited a significant and sustained reduction in LVDP during the 45 minutes of reperfusion compared to sham. I/R $(n=7)$ and $\mathrm{I} / \mathrm{R}+\mathrm{PMN}+\mathrm{BH}_{4}(n=6)$ groups exhibited significant restoration of LVDP during the 45 minutes reperfusion compared to $\mathrm{I} / \mathrm{R}+\mathrm{PMN}$ group. All values are expressed as mean $\pm \mathrm{SEM}$. $\left({ }^{*} P<.05\right.$, from $\mathrm{I} / \mathrm{R}+\mathrm{PMN}$ values $)$.

3.4. Cardiac Effects of $\mathrm{BH}_{4}$ or $\mathrm{BH}_{2}$ on PMN-Induced $\mathrm{MI} / \mathrm{R}$ Injury. Different doses of $\mathrm{BH}_{4}$ or $\mathrm{BH}_{2}$, were applied individually to the isolated PMN-induced MI/R hearts to determine their effects on postreperfused cardiac function. Figure 4 shows the time course of cardiac contractile function (LVDP) for the sham, I/R, I/R+PMN, I/R+PMN+BH $(10 \mu \mathrm{M})$, and $\mathrm{I} / \mathrm{R}+\mathrm{PMN}+\mathrm{BH}_{2}(100 \mu \mathrm{M})$ groups. It illustrates the changes in LVDP during the 80 -minute perfusion period. The hearts in the sham group maintained LVDP throughout the entire duration of the perfusion period ( $96 \pm 3 \%$ of initial baseline values). I/R group hearts experienced a minor depression in LVDP (i.e., down to $79 \%$ of initial baseline) during the initial 5 minutes of reperfusion, but by the end of reperfusion they had recovered to $100 \pm 10 \%$ of initial baseline values. By contrast, hearts in the I/R+PMN group exhibited sustained cardiac contractile dysfunction, only recovering to $53 \pm 7 \%$ of initial baseline values at 45 -minute reperfusion. However, $\mathrm{BH}_{4}(10 \mu \mathrm{M})$ given during early reperfusion (i.e., first 5 minutes) significantly increased LVDP at 30, 40, and 45 minutes postreperfusion compared to $\mathrm{I} / \mathrm{R}+\mathrm{PMN}$ hearts (all $P<.05)$ and recovered to $85 \pm 8 \%$ of initial baseline. By contrast, LVDP time course in $\mathrm{BH}_{2}(100 \mu \mathrm{M})$-treated group

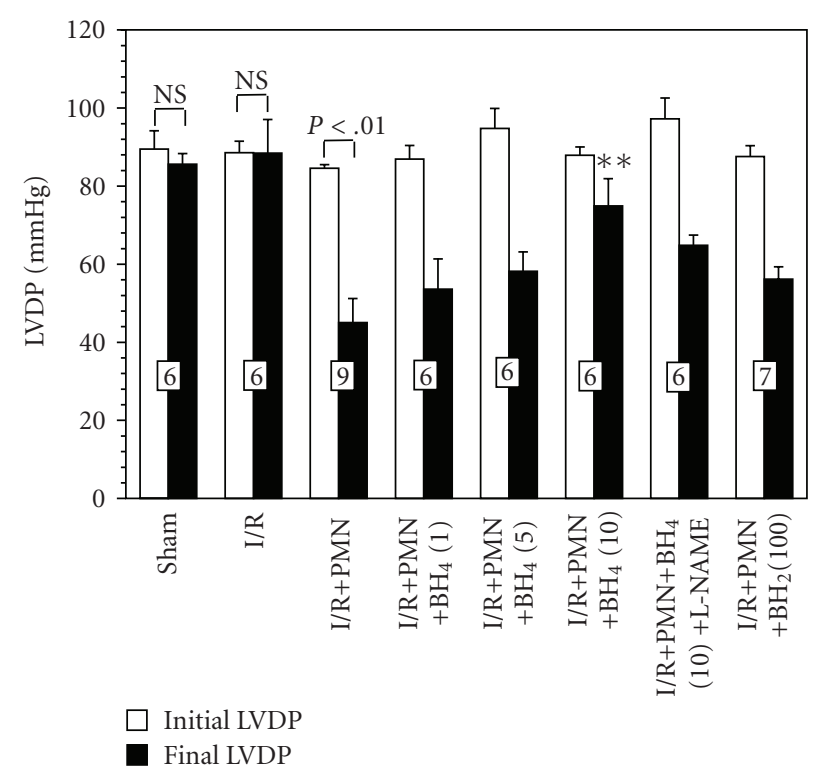

FIGURE 5: Initial and final LVDP expressed in mmHg from different experimental groups. Hearts were perfused in the presence or absence of PMNs. PMNs induced a significant decrease in LVDP, which was attenuated by the $\mathrm{BH}_{4}(10 \mu \mathrm{M})$, not by $\mathrm{BH}_{2}(100 \mu \mathrm{M})$. L-NAME $(50 \mu \mathrm{M})$ blocked the cardioprotective effect of $\mathrm{BH}_{4}$ treatment. All values are expressed as mean \pm SEM. Numbers of hearts are at the bottom of the bars. All drugs are in $\mu \mathrm{M}$ concentrations. $\left({ }^{* *} P<.01\right.$ from final $\mathrm{I} / \mathrm{R}+\mathrm{PMN}$ values; NS, not significant compared to initial LVDP values).

was similar to that of I/R+PMN group (Figure 4). This data suggests that $\mathrm{BH}_{4}$ treatment, not $\mathrm{BH}_{2}$ treatment, provided significant restoration in postreperfused LVDP.

Figures 5 and 6 showed the initial and final values for LVDP and $+d P / d t_{\max }$ from the control and different treated groups, respectively. There was no significant difference between the initial baseline values of all the groups studied. There was also no significant difference between the initial and final values of LVDP and $+d P / d t_{\max }$ for the sham and I/R groups. In order to establish whether the $\mathrm{BH}_{4}$ or $\mathrm{BH}_{2}$ produced any direct inotropic effects on cardiac contractile function, sham and I/R hearts were perfused with $\mathrm{BH}_{4}(10 \mu \mathrm{M})$ or $\mathrm{BH}_{2}(100 \mu \mathrm{M})$. The $\mathrm{BH}_{4}(10 \mu \mathrm{M})$ or $\mathrm{BH}_{2}$ $(100 \mu \mathrm{M})$ treated sham and I/R hearts maintained a similar cardiac function with respect to initial and final LVDP and $+d P / d t_{\max }$, indicating that $\mathrm{BH}_{4}(10 \mu \mathrm{M})$ or $\mathrm{BH}_{2}(100 \mu \mathrm{M})$ has no direct effect on cardiac contractile function, even in the setting of I/R without PMNs (data not shown).

However, $\mathrm{I} / \mathrm{R}+\mathrm{PMN}$ hearts only recovered to $53 \pm 7 \%$ of initial LVDP and $45 \pm 7 \%$ of initial $+d P / d t_{\max }$ at 45 minutes post-reperfusion, both were significantly lower than initial baselines (Figures 5 and 6 , both $P<.01$ ). This result suggests that $\mathrm{PMNs}$ are principally responsible for the sustained cardiac contractile dysfunction in this model of MI/R. We have previously shown that the amount of PMNs used in this model does not elicit cardiodepressant effects in sham hearts [19]. Collectively, these data indicate that the combination of 20-minute ischemia followed by 45 -minute 


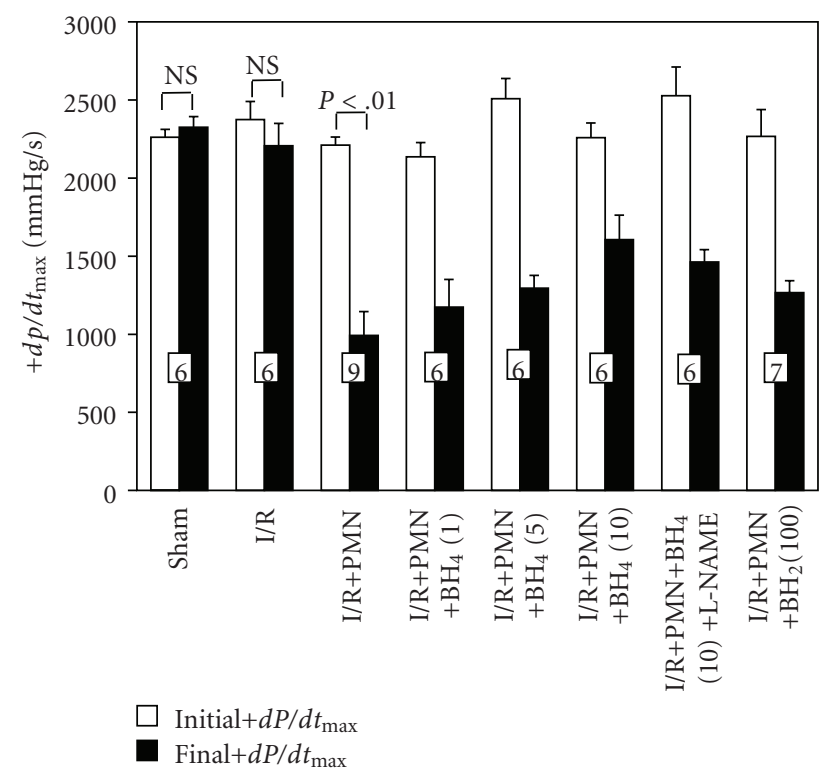

Figure 6: Initial and final $+d P / d t_{\max }$ expressed in $\mathrm{mmHg} / \mathrm{s}$ from different experimental groups. Hearts were perfused in the presence or absence of PMNs. PMNs induced a significant decrease in $+d P / d t_{\max }$. Neither $\mathrm{BH}_{4}(10 \mu \mathrm{M})$ nor $\mathrm{BH}_{2}(100 \mu \mathrm{M})$ treatment significantly improved $+d P / d t_{\max }$ compared to $\mathrm{I} / \mathrm{R}+\mathrm{PMN}$ hearts. All values are expressed as mean \pm SEM. Numbers of hearts are at the bottom of the bars. All drugs are in $\mu \mathrm{M}$ concentrations. (NS, not significant compared to initial LVDP values).

reperfusion in the presence of PMNs is required to sustain cardiac contractile dysfunction.

To test the effect of $\mathrm{BH}_{4}$ on the PMN-induced post I/R cardiac dysfunction, we applied this drug during the first 5 minutes of reperfusion. $\mathrm{BH}_{4}$ exerted a dose-dependent effect on restoring postreperfused LVDP and $+d P / d t_{\max } .1$ and $5 \mu \mathrm{M} \mathrm{BH}$ treated $\mathrm{I} / \mathrm{R}+\mathrm{PMN}$ hearts finally recovered to $62 \pm 9 \%$ and $61 \pm 5 \%$ of initial LVDP, respectively, and both were not significantly different from the final values of the $\mathrm{I} / \mathrm{R}+\mathrm{PMN}$ group (Figure 5 ). However, $10 \mu \mathrm{M} \mathrm{BH}$ exhibited significant restoration in final LVDP $(85 \pm 8 \%$ of initial baseline) compared to that of $\mathrm{I} / \mathrm{R}+\mathrm{PMN}$ hearts (53 $\pm 7 \%$ of initial baseline). By contrast, final $+d P / d t_{\max }$ in 1 , 5 , and $10 \mu \mathrm{M} \mathrm{BH}_{4}$-treated $\mathrm{I} / \mathrm{R}+\mathrm{PMN}$ hearts were $55 \pm 8 \%$, $52 \pm 3 \%$, and $71 \pm 7 \%$ of initial values, respectively, but were not significantly different from the final $+d P / d t_{\max }$ of the $\mathrm{I} / \mathrm{R}+\mathrm{PMN}$ hearts (Figure 6). This data suggests that $\mathrm{BH}_{4}$ treatment during the early reperfusion can partially improve post I/R cardiac contractile function.

On the other hand, application of $\mathrm{BH}_{2}(100 \mu \mathrm{M})$ during the first 5 minutes of reperfusion did not restore postreperfusion cardiac contractile function in the presence of activated PMNs. The $\mathrm{I} / \mathrm{R}+\mathrm{PMN}+\mathrm{BH}_{2}(100 \mu \mathrm{M})$ hearts recovered to $64 \pm 4 \%$ and $56 \pm 3 \%$ for LVDP and $+d P / d t_{\max }$ of initial baseline at 45 -minute postreperfusion, respectively. These values were not significantly different from the final values of $\mathrm{I} / \mathrm{R}+\mathrm{PMN}$ control group (Figures 5 and 6 ). Moreover, the cardiac function in $\mathrm{BH}_{2}$-treated animals was not different from $\mathrm{I} / \mathrm{R}+\mathrm{PMN}$ control hearts at any time point during the reperfusion. This data suggests that $\mathrm{BH}_{2}$ treatment exhibited the similar compromised postreperfused cardiac function as the $\mathrm{I} / \mathrm{R}+\mathrm{PMN}$ control group.

3.5. Effects of L-NAME on Cardioprotective Effects of $\mathrm{BH}_{4}$. To further determine if a $\mathrm{NO}$ mechanism is involved in the cardioprotection of $\mathrm{BH}_{4}(10 \mu \mathrm{M})$ application during reperfusion, a NOS inhibitor, L-NAME $(50 \mu \mathrm{M})$, was perfused throughout the 45-minute reperfusion. Previous studies have shown that L-NAME given by itself during reperfusion is not associated with cardioprotection [23]. The cardioprotective effects of $\mathrm{BH}_{4}(10 \mu \mathrm{M})$ were blocked by LNAME suggesting that a $\mathrm{NO}$ mechanism was principally responsible for mediating the cardioprotective effects of $\mathrm{BH}_{4}$. The final LVDP and $+d P / d t_{\max }$ values in this group of hearts were only $67 \pm 3 \%$ and $58 \pm 3 \%$ of the initial baseline, respectively, and were not significantly different from the final values of the IR+PMN group (Figures 5 and 6).

3.6. Effects of $\mathrm{BH}_{4}$ or $\mathrm{BH}_{2}$ on Postreperfused PMNs Adherence/Infiltration. The infiltration of PMNs into the myocardium within the 45-minute reperfusion period is closely correlated with the cardiac injury associated with $\mathrm{I} / \mathrm{R}$ in this model. Therefore, PMN vascular adherence and myocardial infiltration were determined for each experimental group. The representative PMN coronary vascular adherence and transmigration from $\mathrm{I} / \mathrm{R}+\mathrm{PMN}$ and $\mathrm{I} / \mathrm{R}+\mathrm{PMN}+$ $\mathrm{BH}_{4}(10 \mu \mathrm{M})$ groups were shown by light microscopy under 20x, 40x, and 100x magnification (Figure 7). Arrowheads indicate PMN adherence to the coronary vascular endothelium, while arrows indicate PMNs that have infiltrated into the myocardium. $\mathrm{I} / \mathrm{R}+\mathrm{PMN}+\mathrm{BH}_{4}(10 \mu \mathrm{M})$ hearts displayed a considerable reduction in PMN vascular adherence and tissue infiltration compared to $\mathrm{I} / \mathrm{R}+\mathrm{PMN}$ hearts.

The total and adhered intravascular PMNs from different experimental groups are shown in Figure 8. Sham and I/R hearts exhibited very few vascular adhered and transmigrated PMNs in the postreperfused heart tissue, which represents only resident PMNs. However, I/R+PMN hearts exhibited a significantly increased total intravascular and infiltrated PMNs (208 PMNs $/ \mathrm{mm}^{2}$ in $\mathrm{I} / \mathrm{R}+\mathrm{PMN}$ versus $20 \mathrm{PMNs} / \mathrm{mm}^{2}$ in sham), as well as vascular adhered PMNs (71 PMNs $/ \mathrm{mm}^{2}$ in $\mathrm{I} / \mathrm{R}+\mathrm{PMN}$ versus $<2 \mathrm{PMNs} / \mathrm{mm}^{2}$ in sham). Similarly, $\mathrm{BH}_{2}$-treated hearts also showed significantly higher total $\left(208 \mathrm{PMNs} / \mathrm{mm}^{2}\right)$ and vascular adhered PMNs $\left(73 \mathrm{PMNs} / \mathrm{mm}^{2}\right)$. By contrast, $\mathrm{BH}_{4}$ treated hearts exhibited a dose-dependent decrease in total and vascular adhered PMNs. The I/R+PMN $+\mathrm{BH}_{4}(10 \mu \mathrm{M})$ hearts showed significantly less adhered PMNs (34 PMNs $/ \mathrm{mm}^{2}$ ) and total PMNs $\left(109 \mathrm{PMNs} / \mathrm{mm}^{2}\right.$ ) compared to those of I/R+PMN hearts (both $P<.01$ ). Furthermore, L-NAME blocked the attenuation of total intravascular and infiltrated PMNs by $\mathrm{BH}_{4}$ application during reperfusion (Figure 8).

\section{Discussion}

4.1. Summary of Major Findings. The major findings of this study were as follows. (1) $\mathrm{BH}_{4}$ promoted $\mathrm{NO}$ release from vascular endothelium in a dose-dependent manner, whereas 


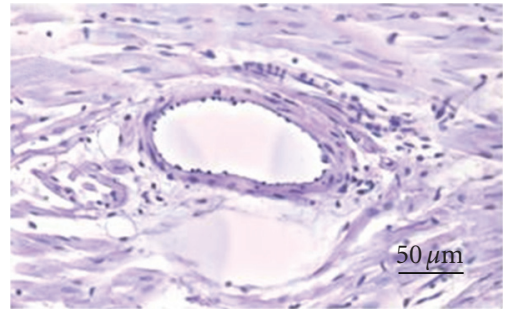

(a)

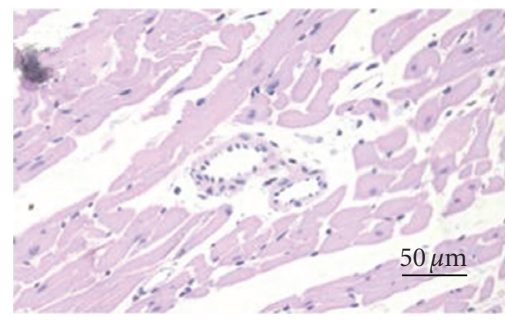

(d)

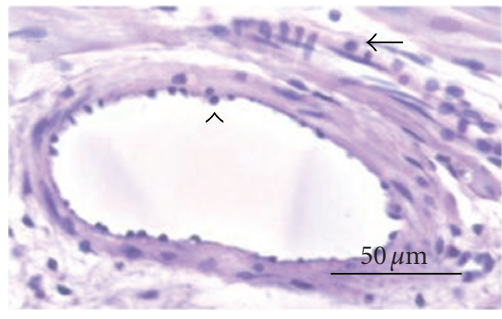

(b)

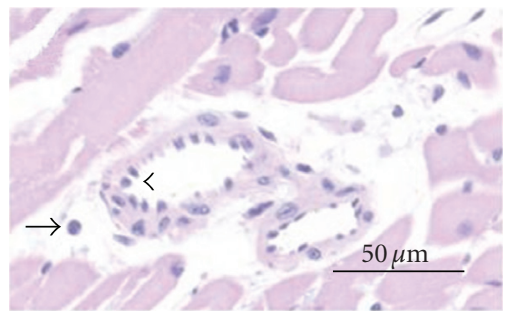

(e)

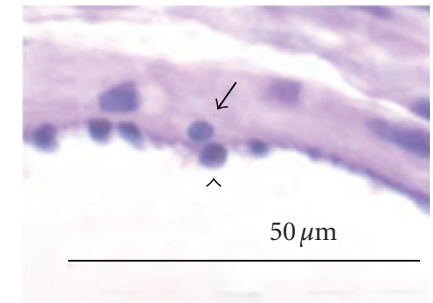

(c)

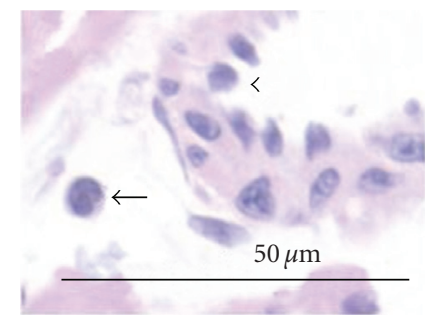

(f)

FIGURE 7: Light microscopy photograph of hematoxylin and eosin-stained rat heart tissue from I/R+PMN and I/R+PMN+BH $4(10 \mu \mathrm{M})$. (a)(c), I/R+PMN heart illustrated enhanced PMN coronary vascular adherence and tissue infiltration ((a): 20x; (b): 40x; (c): 100x). (d)-(f), $\mathrm{I} / \mathrm{R}+\mathrm{PMN}+\mathrm{BH}_{4}(10 \mu \mathrm{M})$ heart exhibited a reduction in PMN coronary vascular adherence and tissue infiltration compared with $\mathrm{I} / \mathrm{R}+\mathrm{PMN}$ ((d): 20x; (e): 40x; (f): 100x). Arrows indicate infiltrated PMN and arrowheads indicate PMN adherence to coronary vasculature. Scale bar, $50 \mu \mathrm{m}$.

$\mathrm{BH}_{2}$ decreased $\mathrm{NO}$ release in nonischemic rat aortic segments. (2) The increased oxidative stress (i.e., $\mathrm{H}_{2} \mathrm{O}_{2}$ ) during reperfusion was significantly decreased by $\mathrm{BH}_{4}(6.5 \mathrm{mg} / \mathrm{kg})$ in femoral $\mathrm{I} / \mathrm{R}$ veins in vivo. (3) $\mathrm{BH}_{2}(4 \mathrm{mg} / \mathrm{kg})$ applied at the beginning of reperfusion significantly decreased NO release during reperfusion, whereas $\mathrm{BH}_{4}(6.5 \mathrm{mg} / \mathrm{kg})$ significantly increased $\mathrm{NO}$ release compared to $\mathrm{BH}_{2}$ treatment in femoral $\mathrm{I} / \mathrm{R}$ veins in vivo. (4) $\mathrm{BH}_{4}(10 \mu \mathrm{M})$, not $\mathrm{BH}_{2}(100 \mu \mathrm{M})$ treated $\mathrm{I} / \mathrm{R}+\mathrm{PMN}$ hearts, exerted significant restoration in LVDP, which was associated with significant attenuation of intravascular PMN adherence/infiltration in postreperfused myocardium. (5) The cardioprotective effects of $\mathrm{BH}_{4}$ on cardiac contractile function and infiltrated/adhered PMNs were blocked by L-NAME.

4.2. Contribution of $\mathrm{BH}_{4}$ to eNOS Coupling and $\mathrm{BH}_{2}$ to eNOS Uncoupling. It is well known that $\mathrm{BH}_{4}$ is an essential cofactor of eNOS to produce NO by maintaining eNOS in the coupled state via facilitating the binding of $\mathrm{L}$-arginine to the heme site of eNOS $[7,9]$. By contrast, $\mathrm{BH}_{2}$, or decreased ratio between $\mathrm{BH}_{4}$ and $\mathrm{BH}_{2}$, can result in the uncoupled state of eNOS in that $\mathrm{L}$-arginine is not bound to the heme site and molecular oxygen is used as the substrate to produce SO instead of NO (see Figure 9) [9-11, 13]. Therefore, in the nonischemic aortic segments, we found that $\mathrm{BH}_{4}$ dose dependently increased $\mathrm{NO}$ release by promoting eNOS coupling to produce more NO. By contrast, $\mathrm{BH}_{2}$ dose dependently decreased NO release from aortic segments. This trend of decreasing $\mathrm{NO}$ bioavailability by $\mathrm{BH}_{2}$ may be because $\mathrm{BH}_{2}$ promotes eNOS uncoupling and facilitates eNOS to produce SO instead of NO, which further quenches NO via the formation of peroxynitrite [9].
Furthermore, we found similar effects of $\mathrm{BH}_{4}$ and $\mathrm{BH}_{2}$ on NO release in femoral I/R. There was a slight decrease in $\mathrm{NO}$ release (i.e., 6-7 nM) from femoral veins in the I/R limb compared to the sham limb in the saline control group. By contrast, applying $\mathrm{BH}_{2}$ at the beginning of reperfusion significantly decreased NO release from 15 minutes and throughout the rest of reperfusion. However, administration of $\mathrm{BH}_{4}$ during the early reperfusion significantly increased $\mathrm{NO}$ release in comparison to $\mathrm{BH}_{2}$ treatment. This data suggests that under $\mathrm{I} / \mathrm{R}$ conditions, $\mathrm{BH}_{2}$ can further facilitate eNOS uncoupling and further reduce $\mathrm{NO}$ release (i.e., in nM concentration), whereas $\mathrm{BH}_{4}$ may help eNOS maintain the coupled state and increase NO bioavailability. The in vivo data from this study further supports in vitro data regarding the role of $\mathrm{BH}_{4}$ and $\mathrm{BH}_{2}$ in eNOS coupling and uncoupling $[7,11]$.

On the other hand, the effects of $\mathrm{BH}_{4}$ and $\mathrm{BH}_{2}$ on $\mathrm{H}_{2} \mathrm{O}_{2}$ release in femoral $\mathrm{I} / \mathrm{R}$ also demonstrate the contribution of eNOS to the oxidative stress during reperfusion. It is well known that $\mathrm{H}_{2} \mathrm{O}_{2}$ is a good indicator of oxidative stress with a longer half-life (i.e., $\mathrm{min}$ ) compared to $\mathrm{SO}$ (i.e., sec) [12]. By directly measuring $\mathrm{H}_{2} \mathrm{O}_{2}$ release from femoral veins in a rat femoral I/R model, we found that $\mathrm{H}_{2} \mathrm{O}_{2}$ release from the I/R limb was significantly higher throughout the whole 45 -minute reperfusion period compared to the sham limb. This result provides direct evidence to show the oxidative stress during the early reperfusion. Furthermore, the administration of $\mathrm{BH}_{4}$ at the beginning of reperfusion significantly decreased $\mathrm{H}_{2} \mathrm{O}_{2}$ release. This data suggests that maintenance of eNOS coupling by $\mathrm{BH}_{4}$ at the start of reperfusion would help to attenuate the oxidative stress. 


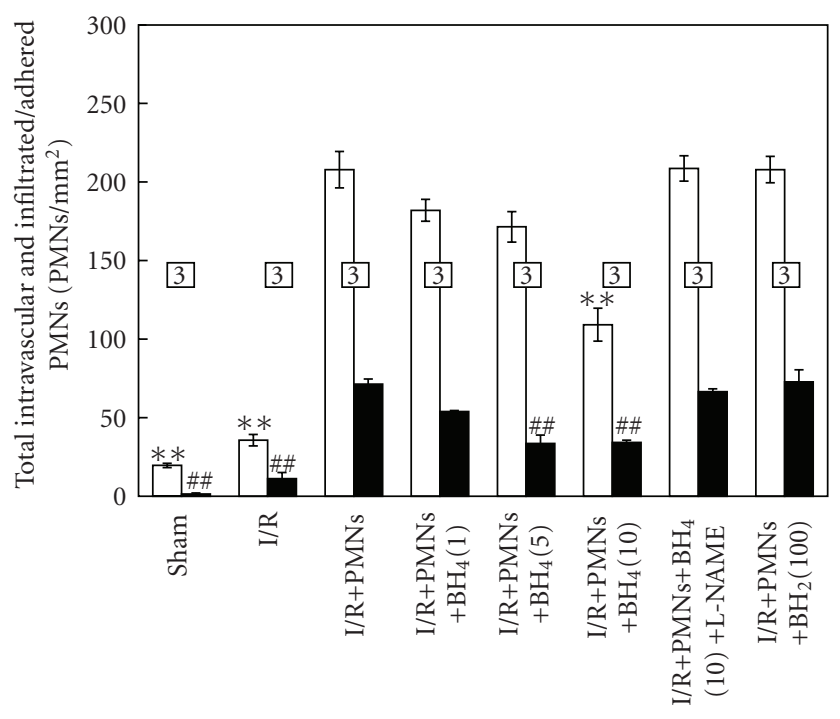

Total intravascular and infiltrated PMNs

Adhered intravascular PMNs

FIGURE 8: Histological assessment of total intravascular/infiltrated PMNs and vascular adhered PMNs in isolated postreperfused rat heart tissue from different experimental groups. The total intravascular/infiltrated $\mathrm{PMN}$ in sham, $\mathrm{I} / \mathrm{R}$ and $\mathrm{I} / \mathrm{R}+\mathrm{PMN}+\mathrm{BH}_{4}$ $(10 \mu \mathrm{M})$ groups were significantly reduced compared to that in I/R+PMN group. Similarly, the vascular adhered PMNs in sham, $\mathrm{I} / \mathrm{R}, \mathrm{I} / \mathrm{R}+\mathrm{PMN}+\mathrm{BH}_{4}(5 \mu \mathrm{M})$, and $\mathrm{I} / \mathrm{R}+\mathrm{PMN}+\mathrm{BH}_{4}(10 \mu \mathrm{M})$ groups were also significantly reduced compared to that in $\mathrm{I} / \mathrm{R}+\mathrm{PMN}$ group. All values are expressed as mean \pm SEM. Numbers of samples are listed in the box with the bars. All drugs are in $\mu \mathrm{M}$ concentrations. $\left({ }^{* *} P<.01\right.$ from total intravascular/infiltrated PMNs in $\mathrm{I} / \mathrm{R}+\mathrm{PMN}$ group; ${ }^{\# \#} \mathrm{P}<.01$ from vascular adhered $\mathrm{PMNs}$ in $\mathrm{I} / \mathrm{R}+\mathrm{PMN}$ group).

By contrast, $\mathrm{BH}_{2}$ treatment during reperfusion maintained eNOS uncoupling, which is involved in mediating oxidative stress observed during the reperfusion. $\mathrm{BH}_{2}$ treatment resulted in the similar $\mathrm{H}_{2} \mathrm{O}_{2}$ increase to the saline control throughout the reperfusion. It is possible that increasing $\mathrm{BH}_{2}$ to $\mathrm{BH}_{4}$ ratio by itself may not make a significant contribution to enhance the oxidative stress release compared to the saline control. As shown previously, $\mathrm{BH}_{2}$ significantly decreased $\mathrm{NO}$ release compared to saline control during reperfusion, and this decrease was in the range of 150 to $200 \mathrm{nM}$, which is 10 to 15 times less the amount of $\mathrm{H}_{2} \mathrm{O}_{2}$ change (i.e., micromolar range). It may be plausible to speculate that significant changes in NO release in the nanomolar range can be observed with $\mathrm{BH}_{2}$ compared to micromolar differences in $\mathrm{H}_{2} \mathrm{O}_{2}$ release. It is well known that $\mathrm{BH}_{2}$ binds with equal affinity as $\mathrm{BH}_{4}$ to the eNOS oxygenase domain, and can displace $\mathrm{BH}_{4}$ binding to facilitate eNOS uncoupling [13]. To further promote additional eNOS uncoupling, it would be necessary to increase eNOS activity, such as with a protein kinase $\mathrm{C}$ ( $\mathrm{PKC}$ ) epsilon activator, combined with additional $\mathrm{BH}_{2}$. Conversely, supplementing $\mathrm{BH}_{4}$ under increased eNOS activity conditions may promote additional eNOS coupling that otherwise would not be observed under constitutive eNOS activity conditions [24].

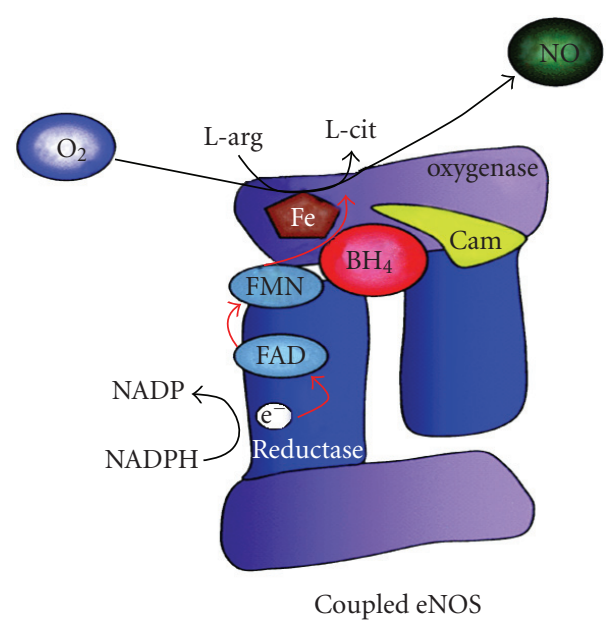

(a)

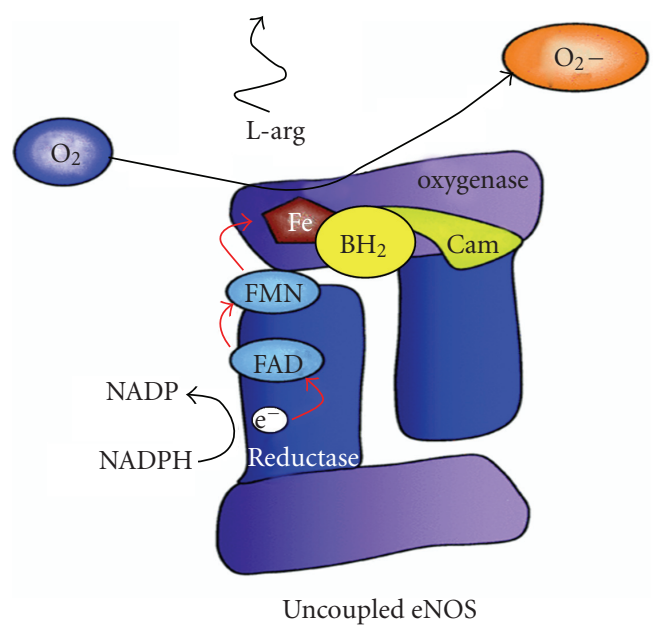

(b)

FIGURE 9: Schematic diagram of eNOS coupling and uncoupling. $\mathrm{BH}_{4}$ binds to the heme oxygenase domain to promote L-arginine substrate binding under eNOS coupling conditions. By contrast, $\mathrm{BH}_{2}$ competes with $\mathrm{BH}_{4}$ at the heme oxygenase domain and promotes molecular oxygen as substrate to produce superoxide and eNOS uncoupling conditions (Adopted from [9]).

These experiments would be important to identify the overall significance of eNOS coupling/uncoupling contribution to the restoration/impairment of blood vessel and organ function during reperfusion. Moreover, these experiments would also identify a potential therapeutic tool that could be used clinically in patients suffering from reperfusion injury by ischemic-induced heart attack, coronary bypass/angioplasty and organ transplantation.

4.3. The Role of $\mathrm{BH}_{4}$ and $\mathrm{BH}_{2}$ on Postreperfused Cardiac Function and PMN Adherence/Infiltration. Previous studies have shown the effectiveness of $\mathrm{BH}_{4}$ in restoring postreperfused cardiac function [15]. However, these studies also gave $\mathrm{BH}_{4}$ prior to ischemia in addition to giving $\mathrm{BH}_{4}$ during the reperfusion. By contrast, our studies only gave $\mathrm{BH}_{4}$ during reperfusion. This point is important in that pretreatment 
of tissue or organs prior to invasive surgical procedures (i.e., organ transplantation) is not always a feasible option. Therefore, in our study, $\mathrm{BH}_{4}$ is only given during the first 5 minutes of reperfusion. We found that $\mathrm{BH}_{4}$ treatment exerted partial restoration in postreperfused cardiac function, which is associated with significantly less PMN vascular adherence and tissue infiltration. The uniqueness of our study is that we only evaluate the effects of $\mathrm{BH}_{4}$ during the reperfusion phase and clinically this approach may be more feasible in that $\mathrm{BH}_{4}$ could be administered immediately following coronary artery bypass and organ transplantation procedures.

Despite that $\mathrm{BH}_{4}$-treated $\mathrm{I} / \mathrm{R}+\mathrm{PMN}$ hearts exhibited $85 \%$ postreperfused LVDP, $+d P / d t_{\max }$ only recovered by $71 \%$ and was not significantly increased compared to I/R+PMN control hearts. This may be due to saturation of eNOS coupling with adding $\mathrm{BH}_{4}$ which may slow down the recovery of postreperfused $+d P / d t_{\max }$. By contrast, $\mathrm{BH}_{2}$-treated hearts did not show any improvements in postreperfused heart function suggesting that $\mathrm{BH}_{2}$ maintained eNOS uncoupling. The postreperfused heart function in $\mathrm{BH}_{2}$-treated hearts was similar to $\mathrm{I} / \mathrm{R}+\mathrm{PMN}$ control hearts, which suggest that $\mathrm{BH}_{2}$ did not further increase oxidative stress and is consistent with the femoral $\mathrm{I} / \mathrm{R}_{2} \mathrm{O}_{2}$ release data. In future studies, we plan to evaluate the role of eNOS uncoupling by increasing eNOS activity combined with $\mathrm{BH}_{2}$ for any potential additive or synergistic effect. To test this hypothesis, increasing eNOS activity during reperfusion with a PKC epsilon activator combined with the same concentration of $\mathrm{BH}_{2}$ should result in greater oxidative stress and lead to a more compromised postreperfused cardiac function since these conditions would promote more $\mathrm{BH}_{2}$ to interact with eNOS [25]. Conversely, adding $\mathrm{BH}_{4}$ with increased eNOS activity (i.e., PKC epsilon activator) would promote more $\mathrm{BH}_{4}$ to interact with eNOS to produce more NO and optimally improve postreperfused $+d P / d t_{\max }$

Alternatively, inhibiting eNOS only during reperfusion with a PKC epsilon inhibitor would also attenuate oxidative stress and restore postreperfused cardiac function regardless of $\mathrm{BH}_{4}$-to- $\mathrm{BH}_{2}$ ratio as suggested from previous work showing restoration of postreperfused cardiac function with PKC epsilon inhibitor in an acute $\mathrm{I} / \mathrm{R}$ and heart transplantation models $[12,26]$. In contrast to PKC epsilon inhibitor, L-NAME does not inhibit SO release from eNOS [11]. LNAME competes with L-arginine at the heme site of the eNOS oxygenase domain to inhibit the production of NO. However, L-NAME will not inhibit the electron reduction of molecular oxygen to $\mathrm{SO}$ at the site when $\mathrm{BH}_{2}$-to- $\mathrm{BH}_{4}$ ratio is increased [11]. It is conceivable that L-NAME would therefore block the cardioprotective effects of $\mathrm{BH}_{4}$ since it is competing with L-arginine as a substrate as shown in Figures 5 and 6.

4.4. Significance of Findings. In summary, this study further supports the conception of $\mathrm{BH}_{4}$ promoting eNOS coupling during I/R. By contrast, $\mathrm{BH}_{2}$ treatment may maintain the eNOS uncoupled state during $\mathrm{I} / \mathrm{R}$ and is associated with compromised postreperfused cardiac function and increased oxidative stress. Moreover, the connection of eNOS coupling or uncoupling to I/R injury, especially during the reperfusion, may encourage a novel optimal treatment strategy for clinical cases.

\section{Acknowledgments}

Christine Hammond (Philadelphia College of Osteopathic Medicine) assisted in the light microscopy photography of the hematoxylin and eosin-stained isolated rat perfused heart tissue sections. This study was supported by the National Heart, Lung, and Blood Institute Grant 1R 15HL-76235-02. This study was also supported in part by the Philadelphia College of Osteopathic Medicine, Department of Pathology, Microbiology, and Immunology and Forensic Medicine and the Center for the Study of Chronic Disorders of Aging at Philadelphia College of Osteopathic Medicine (4170 City Avenue, Philadelphia, PA 19131, PA).

\section{References}

[1] B. R. Lucchesi and K. M. Mullane, "Leukocytes and ischemiainduced myocardial injury," Annual Review of Pharmacology and Toxicology, vol. 26, pp. 201-224, 1986.

[2] M. B. Forman, D. W. Puett, and R. Virmani, "Endothelial and myocardial injury during ischemia and reperfusion: pathogenesis and therapeutic implications," Journal of the American College of Cardiology, vol. 13, no. 2, pp. 450-459, 1989.

[3] A. M. Lefer and D. J. Lefer, "The role of nitric oxide and cell adhesion molecules on the microcirculation in ischaemiareperfusion," Cardiovascular Research, vol. 32, no. 4, pp. 743751, 1996.

[4] P. S. Tsao, N. Aoki, D. J. Lefer, G. Johnson III, and A. M. Lefer, "Time course of endothelial dysfunction and myocardial injury during myocardial ischemia and reperfusion in the cat," Circulation, vol. 82, no. 4, pp. 1402-1412, 1990.

[5] P. S. Tsao and A. M. Lefer, "Time course and mechanism of endothelial dysfunction in isolated ischemic- and hypoxicperfused rat hearts," American Journal of Physiology, vol. 259, no. 6, part 2, pp. H1660-H1666, 1990.

[6] P. R. Hansen, "Role of neutrophils in myocardial ischemia and reperfusion," Circulation, vol. 91, no. 6, pp. 1872-1885, 1995.

[7] J. Vasquez-Vivar, B. Kalyanaraman, and P. Martásek, “The role of tetrahydrobiopterin in superoxide generation from eNOS: enzymology and physiological implications," Free Radical Research, vol. 37, no. 2, pp. 121-127, 2003.

[8] B. Lemmer and M. Arraj, "Effect of NO synthase inhibition on cardiovascular circadian rhythms in wild-type and eNOSknock-out mice," Chronobiology International, vol. 25, no. 4, pp. 501-510, 2008.

[9] T. S. Schmidt and N. J. Alp, "Mechanisms for the role of tetrahydrobiopterin in endothelial function and vascular disease," Clinical Science, vol. 113, no. 1-2, pp. 47-63, 2007.

[10] J. Vasquez-Vivar, B. Kalyanaraman, N. Hogg, et al., "Superoxide generation by endothelial nitric oxide synthase: the influence of cofactors," Proceedings of the National Academy of Sciences of the United States of America, vol. 95, no. 16, pp. 9220-9225, 1998.

[11] J. Vasquez-Vivar, P. Martasek, J. Whitsett, J. Joseph, and B. Kalyanaraman, "The ratio between tetrahydrobiopterin and oxidized tetrahydrobiopterin analogues controls superoxide 
release from endothelial nitric oxide synthase: an EPR spin trapping study," Biochemical Journal, vol. 362, no. 3, pp. 733$739,2002$.

[12] J. C.-W. Teng, H. Kay, Q. Chen, et al., "Mechanisms related to the cardioprotective effects of protein kinase $\mathrm{C}$ epsilon $(\mathrm{PKC} \varepsilon)$ peptide activator or inhibitor in rat ischemia/reperfusion injury," Naunyn-Schmiedebergs Archives of Pharmacology, vol. 378, no. 1, pp. 1-15, 2008.

[13] M. J. Crabtree, C. L. Smith, G. Lam, M. S. Goligorsky, and S. S. Gross, "Ratio of 5,6,7,8-tetrahydrobiopterin to 7,8-dihydrobiopterin in endothelial cells determines glucoseelicited changes in NO vs. superoxide production by eNOS," American Journal of Physiology, vol. 294, no. 4, pp. H1530H1540, 2008.

[14] Z. Zhu, N. Takahashi, T. Ooie, T. Shinohara, K. Yamanaka, and T. Saikawa, "Oral administration of geranylgeranylacetone blunts the endothelial dysfunction induced by ischemia and reperfusion in the rat heart," Journal of Cardiovascular Pharmacology, vol. 45, no. 6, pp. 555-562, 2005.

[15] S. Yamashiro, K. Noguchi, Y. Kuniyoshi, K. Koja, and M. Sakanashi, "Role of tetrahydrobiopterin on ischemiareperfusion injury in isolated perfused rat hearts," Journal of Cardiovascular Surgery, vol. 44, no. 1, pp. 37-49, 2003.

[16] J.-P. Guo, T. Murohara, M. Buerke, R. Scalia, and A. M. Lefer, "Direct measurement of nitric oxide release from vascular endothelial cells," Journal of Applied Physiology, vol. 81, no. 2, pp. 774-779, 1996.

[17] D. Omiyi, R. J. Brue, P. Taormina II, M. Harvey, N. Atkinson, and L. H. Young, "Protein kinase C betaII peptide inhibitor exerts cardioprotective effects in rat cardiac ischemia/reperfusion injury," Journal of Pharmacology and Experimental Therapeutics, vol. 314, no. 2, pp. 542-551, 2005.

[18] M. V. Kuntscher, E. U. Schirmbeck, H. Menke, E. Klar, M. M. Gebhard, and G. Germann, "Ischemic preconditioning by brief extremity ischemia before flap ischemia in a rat model," Plastic and Reconstructive Surgery, vol. 109, no. 7, pp. 2398 2404, 2002.

[19] E. E. Peterman, P. Taormina II, M. Harvey, and L. H. Young, "Go 6983 exerts cardioprotective effects in myocardial ischemia/reperfusion," Journal of Cardiovascular Pharmacology, vol. 43, no. 5, pp. 645-656, 2004.

[20] A. Phillipson, E. E. Peterman, P. Taormina, et al., "Protein kinase C-zeta inhibition exerts cardioprotective effects in ischemia-reperfusion injury," American Journal of Physiology, vol. 289, no. 2, pp. H898-H907, 2005.

[21] D. J. Lefer, R. Scalia, B. Campbell, et al., "Peroxynitrite inhibits leukocyte-endothelial cell interactions and protects against ischemia-reperfusion injury in rats," Journal of Clinical Investigation, vol. 99, no. 4, pp. 684-691, 1997.

[22] L. H. Young, Y. Ikeda, R. Scalia, and A. M. Lefer, "Cpeptide exerts cardioprotective effects in myocardial ischemiareperfusion," American Journal of Physiology, vol. 279, no. 4, pp. H1453-H1459, 2000.

[23] Y. Shi, P. Rafiee, J. Su, K. A. Pritchard, J. S. Tweddell, and J. E. Baker, "Acute cardioprotective effects of erythropoietin in infant rabbits are mediated by activation of protein kinases and potassium channels," Basic Research in Cardiology, vol. 99, no. 3, pp. 173-182, 2004.

[24] C. J. Zambrano, S. Krass, Q. Chen, K.-A. Perkins, B. Rueter, and L. H. Young, "Real time measurement of hydrogen peroxide $\left(\mathrm{H}_{2} \mathrm{O}_{2}\right)$ or nitric oxide $(\mathrm{NO})$ in femoral ischemia/reperfusion (I/R): effects of protein kinase $\mathrm{C}(\mathrm{PKC})$ epsilon activator $(\varepsilon+)$ or inhibitor $(\varepsilon-)$ combined with tetrahydrobiopterin $\left(\mathrm{BH}_{4}\right)$ or dihydrobiopterin $\left(\mathrm{BH}_{2}\right)$," The FASEB Journal, vol. 23, pp. 617-619, 2009, abstract 617.19.

[25] K. A. Perkins, S. Pershad, Q. Chen, S. McGraw, J. Adams, and L. H. Young, "Mechanisms related to endothelial nitric oxide synthase (eNOS) uncoupling in myocardial ischemia/reperfusion (MI/R)," The FASEB Journal, vol. 23, no. 4, pp. 793-522, 2009, abstract 793.13.

[26] T. Koyanagi, K. Noguchi, A. Ootani, K. Inagaki, R. C. Robbins, and D. Mochly-Rosen, "Pharmacological inhibition of epsilon PKC suppresses chronic inflammation in murine cardiac transplantation model," Journal of Molecular and Cellular Cardiology, vol. 43, no. 4, pp. 517-522, 2007. 

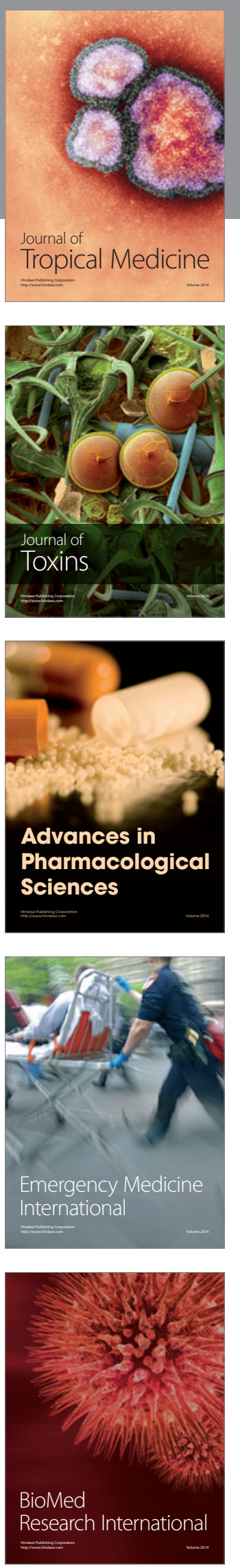
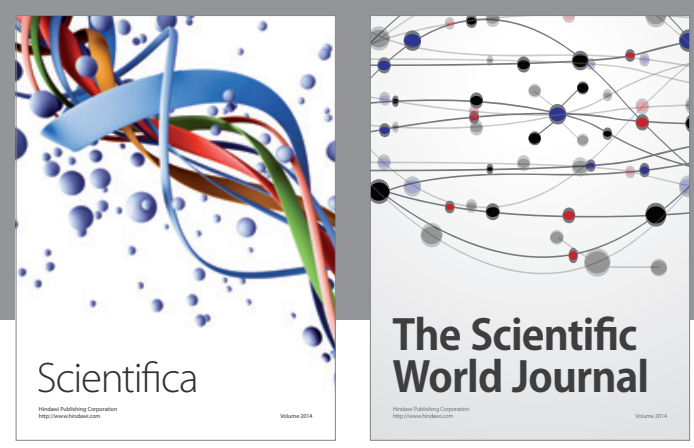

The Scientific World Journal
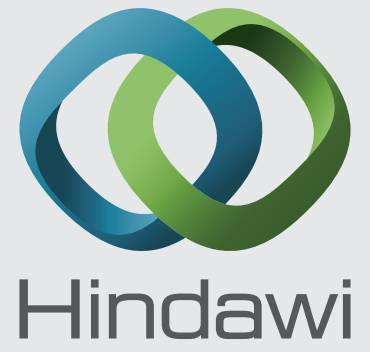

Submit your manuscripts at

http://www.hindawi.com
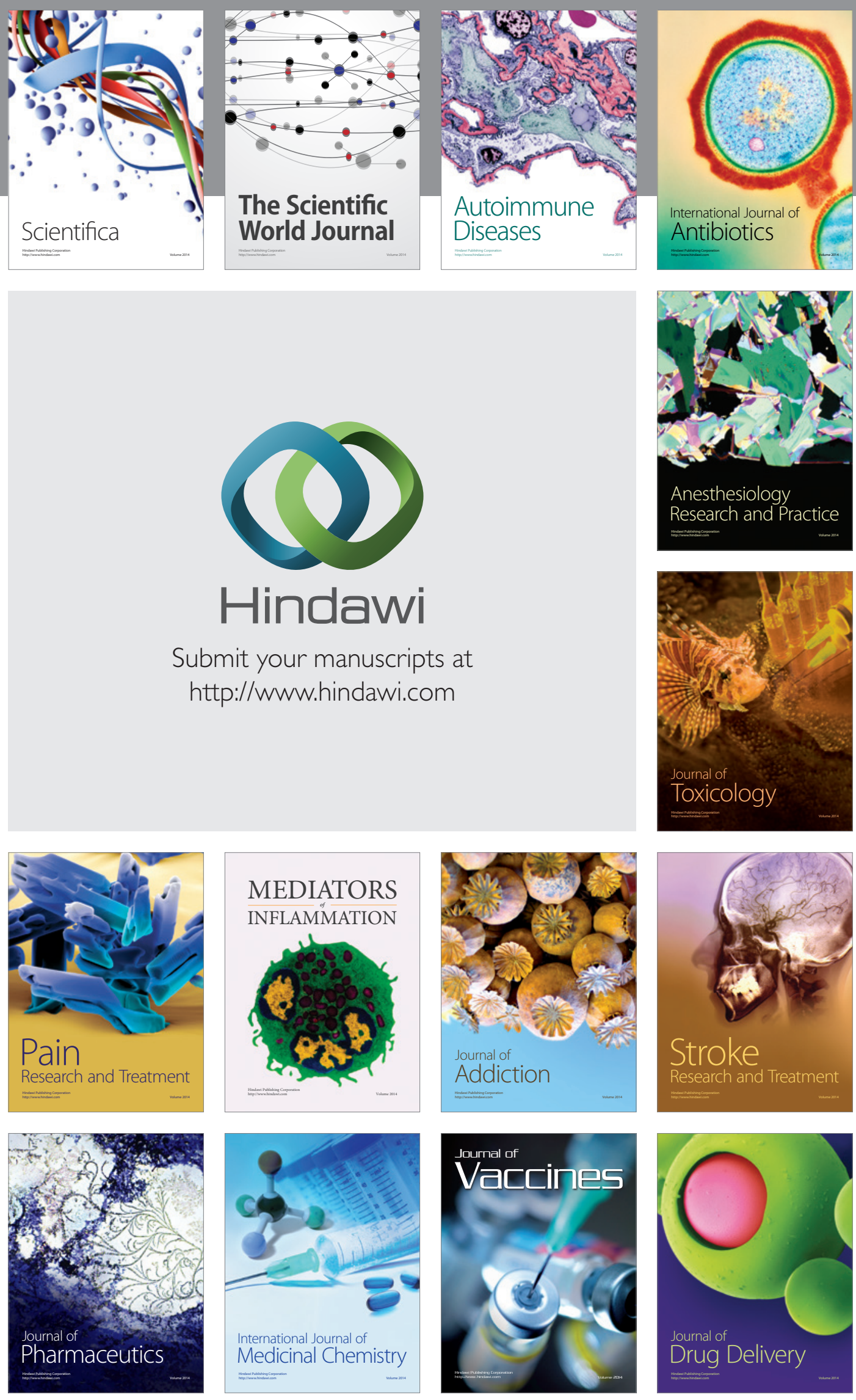